\title{
(2) OPEN ACCESS \\ Patients presenting with metastases: stage IV uveal melanoma, an international study
}

\author{
Gaurav Garg, ${ }^{1}$ Paul T Finger (1) , ${ }^{1}$ Tero T Kivelä, ${ }^{2}$ E Rand Simpson, ${ }^{3}$ Brenda L Gallie, ${ }^{4}$ \\ Svetlana Saakyan, ${ }^{5}$ Anush G Amiryan, ${ }^{5}$ Vladimir Valskiy, ${ }^{5}$ Kimberly J Chin, ${ }^{1}$ \\ Ekaterina Semenova, ${ }^{1}$ Stefan Seregard, ${ }^{6}$ Maria Filì ${ }^{10},{ }^{6}$ Matthew Wilson, ${ }^{7}$ \\ Barrett Haik, ${ }^{7}$ Josep Maria Caminal, ${ }^{8}$ Jaume Catala-Mora, ${ }^{8}$ Cristina Gutiérrez, \\ David E Pelayes, ${ }^{9}$ Anibal Martin Folgar, ${ }_{1}^{9}$ Martine Johanna Jager, ${ }_{1}^{10}$ Mehmet Doğrusöz, ${ }_{1}^{10}$ \\ Gregorius P M Luyten, ${ }^{10}$ Arun D Singh $10,{ }^{11}$ Shigenobu Suzuki, ${ }^{12}$ for the AJCC \\ Ophthalmic Oncology Task Force
}

For numbered affiliations see end of article.

\section{Correspondence to}

Dr Paul T Finger, Department of Ocular Tumor, Orbital Disease, Ophthalmic Radiation Therapy, New York Eye Cancer Center, New York, New York, USA; pfinger@eyecancer.com

This paper was presented as an oral presentation at the $53 \mathrm{rd}$ Annual Scientific Virtual Meeting Retina Society 2020 and as a poster presentation for the 35 th Annual Meeting of American Academy of Ophthalmology.

Received 11 September 2020 Revised 17 November 2020 Accepted 19 November 2020

Check for updates

(C) Author(s) (or their employer(s)) 2021. Re-use permitted under CC BY-NC. No commercial re-use. See rights and permissions. Published by BMJ.

To cite: Garg G, Finger PT, Kivelä TT, et al.

Br J Ophthalmol Epub ahead of print: [please include Day Month Year]. doi:10.1136/

bjophthalmol-2020-317949

\section{ABSTRACT}

Objective To analyse ocular and systemic findings of patients presenting with systemic metastasis. Methods and analysis It is an international, multicentre, internet-enabled, registry-based retrospective data analysis. Patients were diagnosed between 2001 and 2011. Data included: primary tumour dimensions, extrascleral extension, ciliary body involvement, American Joint Committee on Cancer (AJCC)-tumour, node, metastasis staging, characteristics of metastases.

Results Of 3610 patients with uveal melanoma, 69 (1.9\%; $95 \% \mathrm{Cl} 1.5$ to 2.4$)$ presented with clinical metastasis (stage IV). These melanomas originated in the iris, ciliary body and choroid in $4 \%, 16 \%$ and $80 \%$ of eyes, respectively. Using eighth edition AJCC, 8 (11\%), $20(29 \%), 24(35 \%)$, and $17(25 \%)$ belonged to AJCC T-categories T1-T4. Risk of synchronous metastases increased from $0.7 \%$ (T1) to $1.5 \%$ (T2), $2.6 \%$ (T3) and $7.9 \%$ (T4). Regional lymph node metastases (N1a) were detected in $9(13 \%)$ patients of whom $6(67 \%)$ had extrascleral extension. Stage of systemic metastases (known for 40 (59\%) stage IV patients) revealed 14 (35\%), 25 (63\%) and 1 (2\%) had small (M1a), medium-sized (M1b) and large-sized (M1c) metastases, respectively. Location of metastases in stage IV patients were liver $(91 \%)$, lung $(16 \%)$, bone $(9 \%)$, brain $(6 \%)$, subcutaneous tissue (4\%) and others (5\%). Multiple sites of metastases were noted in $24 \%$. Compared with the $98.1 \%$ of patients who did not present with metastases, those with synchronous metastases had larger intraocular tumours, more frequent extrascleral extension, ciliary body involvement and thus a higher AJCC T-category.

Conclusions Though higher AJCC T-stage was associated with risk for metastases at diagnosis, even small T1 tumours were stage IV at initial presentation. The liver was the most common site of metastases; however, frequent multiorgan involvement supports initial whole-body staging.

\section{INTRODUCTION}

Metastasis is the leading cause of death due to uveal melanoma. ${ }^{1-3}$ Many reports have described methods of diagnosis, surveillance and treatment of metastases. In 1985, the Collaborative Ocular Melanoma Study (COMS) employed a combination of physical examination for hepatomegaly, enlarged lymph nodes and subcutaneous nodules as well as ancillary chest X-rays and liver function tests. ${ }^{45}$ Since that time, eye cancer specialists have placed a greater reliance on staging with radiographic imaging especially abdominal ultrasonography (USG), CT, MRI and whole-body positron emission tomography/CT (PET/CT). ${ }^{1-36-10}$

The eye does not have significant lymphatic outflow channels. ${ }^{11}$ Therefore, intraocular melanomas spread through vascular emissaries leading especially to hepatic metastases. However, extrascleral extension allows melanoma cells to access conjunctival lymphatics, leading to rare regional lymph node (RLN) metastases. ${ }^{12} 13$ While the liver is the most commonly reported haematogenous site for metastasis, other sites include bone, lungs, skin and brain. ${ }^{1-8}$ 12-18 Currently, only total-body PET/ CT has been widely available to holistically detect both hepatic and extrahepatic sites of metastatic uveal melanoma. 128

The time of detection of metastases has an effect on the duration of subsequent survival of patients with uveal melanoma. ${ }^{1-3}$ For example, periodic physical examinations, liver function tests and chest $\mathrm{X}$-rays as required by the COMS typically detect late-stage disease leading to less than 6 months of reported survival. ${ }^{4-6} 14$ In contrast, centres employing abdominal radiographic imaging detect otherwise subclinical disease, which is associated with longer term overall survival, typically a median of 12 months. ${ }^{619-27}$ While longer survival has been correlated to early detection or lead-time bias, there exists literature suggesting hepatic metastasectomy, immunotherapy and evolving treatments can sometimes provide cure or prolong life. ${ }^{2} 328-30$

Literature review of PubMed and Medline using the keywords: metastasis, melanoma, uvea, ciliary body, iris and choroid revealed no papers describing the clinical characteristics of a series of patients diagnosed with metastatic uveal melanoma at the time of initial presentation as designated stage IV in the eighth edition American Joint Committee on Cancer (AJCC) tumour, node, metastasis (TNM) 
classification. ${ }^{1}$ This study uses a multicentre, international registry to examine the ocular and systemic findings of patients presenting with systemic uveal melanoma metastasis.

\section{METHODS \\ Definitions}

Group M

Patients with uveal melanoma with metastasis discovered at initial presentation, that is, stage IV disease in the eighth edition AJCC TNM system.

\section{Group N}

Patients with uveal melanoma with no evidence of metastasis at initial presentation, corresponding to stage I-III disease in the eighth edition AJCC TNM system.

\section{The registry}

An internet-based retrospective registry was developed by the American Joint Committee on Cancer Ophthalmic Oncology Task Force (AJCC-OOTF). It comprises data on epidemiology, clinical and pathological aspects of patients with uveal melanoma. ${ }^{15}$ The present research focused on patients who were diagnosed with uveal melanoma metastasis at initial presentation.

\section{Internet database, security and patient protection}

Data entry, storage, patient privacy and statistical analysis were done in accordance with international standards. Data were secured by omitting any personal patient information, secure socket layer encryption, protection against structured query language injection, locking of records and trail auditing by failed login attempts and web page accessing. Each contributing centre had different unique login issued by the coordinating centre and could only access its own data.

\section{Eligibility criteria}

Ten ocular oncology centres from 8 countries (1178 (30.5\%) Canada, 936 (24.3\%) USA, 500 (12.9\%) Russia, 327 (8.4\%) Argentina, 327 (8.4\%) Sweden, 275 (7.1\%) Spain, 255 (6.6\%) The Netherlands and 68 (1.8\%) Japan) for a total of 3866 patients from 4 continents (North and South America, Europe and Asia) participated in this registry. Each centre entered consecutive patients with primary melanoma of the iris, ciliary body and choroid who were diagnosed and treated between 1 April 2001 and 1 April 2011. Each centre utilised its standard methods of surveillance for metastasis that always included: abdominal scanning (USG, CT, MRI) and/or whole-body PET/ CT. In that 256 patients had incomplete records, 3610 (93.4\%) of the 3866 patients were available for this analysis.

\section{Statistical analysis}

Continuous variables were summarised using mean, SD, median and range. Categorical variables were described using frequencies and percentages. For analysis of the significance of intraocular tumour location, we defined tumour origin (iris, ciliary body or choroid) based on the longitudinal centre of the tumour's base. Pearson $\chi^{2}$ test was used to compare contingency tables if the expected frequency was $\geq 5$; otherwise, we used the Fisher's exact test. Univariable and bivariable logistics regression were employed to analyse tumour characteristics as risk factors for synchronous metastasis. Goodness of fit was verified by HosmerLemeshow test. OR and $\mathrm{p}$ values from Wald $\chi^{2}$ test are revealed. SPSS Statistics V.20 software released 2015 was used for all statistical analyses (IBM).

Main $\mathrm{T}$ categories of anatomic extent were defined based on tumour size (largest basal diameter and thickness), whereas ciliary body involvement and extrascleral extension define subcategories. ${ }^{1}$ Tumour size including both tumour thickness and largest basal diameter as independent predictors have been strongly associated with metastasis. ${ }^{15}{ }^{31-33}$ Ciliary body involvement and extrascleral extension have both been found to be an independent risk factor for metastasis. ${ }^{1} 15223134$ Therefore, all these factors were studied separately for a statistically significant risk of synchronous metastasis. Moreover, this was why the eighth edition AJCC classification separated uveal melanoma into anterior or iris melanoma and posterior or ciliary body/ choroidal melanoma anatomical location. ${ }^{1}$

\section{RESULTS}

Of the total cohort of 3610 patients, 69 (1.9\%; 95\% CI 1.5 to 2.4) presented with synchronous primary uveal melanoma and metastases or stage IV disease (group M). The remainder or

Table 1 Primary uveal melanoma presenting with metastasis versus with no metastasis AJCC stage IV uveal melanoma at initial presentatio (group M) $\mathrm{n}=69$

\begin{tabular}{|c|c|c|c|c|c|c|c|}
\hline \multirow{2}{*}{\multicolumn{2}{|c|}{ Characteristics }} & & \\
\hline & & Choroidal & Ciliary body & Iris & Choroidal & Ciliary body & Iris \\
\hline \multicolumn{2}{|l|}{ Sample } & $55(80 \%)$ & $11(16 \%)$ & $3(4 \%)$ & 3097 (87\%) & $266(8 \%)$ & $178(5 \%)$ \\
\hline \multirow{2}{*}{$\begin{array}{l}\text { Tumour thickness } \\
(\mathrm{mm})\end{array}$} & Mean (SD) & $8.3(4.8)$ & $9.6(3.4)$ & N/A & $5.7(3.0)$ & $6.0(3.0)$ & $\mathrm{N} / \mathrm{A}$ \\
\hline & $\begin{array}{l}\text { Median } \\
\text { (range) }\end{array}$ & $7.7(2-0-24.5)$ & $11.0(2.7-14.7)$ & N/A & $5.0(2.0-23.0)$ & $5.6(2.0-16.0)$ & N/A \\
\hline \multirow{2}{*}{$\begin{array}{l}\text { Largest basal } \\
\text { diameter }(\mathrm{mm})^{*}\end{array}$} & Mean (SD) & $14.4(4.7)$ & $10.2(2.6)$ & $6.8(2.0)$ & $12.1(3.8)$ & $10.4(2.8)$ & $3.9(2.7)$ \\
\hline & $\begin{array}{l}\text { Median } \\
\text { (range) }\end{array}$ & $15.0(2.9-25.0)$ & $9.1(6.0-13.8)$ & $6.4(5.0-9.0)$ & $12.0(2.0-30.0)$ & $11.0(2.0-14.0)$ & $3.0(0.5-19.0)$ \\
\hline \multirow[t]{4}{*}{ T-category } & $\mathrm{T} 1$ & $5(9 \%)$ & $1(9 \%)$ & $2(67 \%)$ & 944 (31\%) & $87(33 \%)$ & $92(52 \%)$ \\
\hline & $\mathrm{T} 2$ & $18(33 \%)$ & $2(18 \%)$ & $0(0 \%)$ & $1101(35 \%)$ & $107(40 \%)$ & $84(47 \%)$ \\
\hline & $\mathrm{T} 3$ & $16(29 \%)$ & $7(64 \%)$ & $0(0 \%)$ & $832(27 \%)$ & $67(25 \%)$ & $0(0 \%)$ \\
\hline & $\mathrm{T} 4$ & $16(29 \%)$ & $1(9 \%)$ & $1(33 \%)$ & $220(7 \%)$ & $5(2 \%)$ & $2(1 \%)$ \\
\hline \multicolumn{2}{|l|}{ ESE } & $6(11 \%)$ & $5(45 \%)$ & $1(33 \%)$ & $48(2 \%)$ & $16(6 \%)$ & $2(1 \%)$ \\
\hline \multicolumn{2}{|l|}{$\mathrm{CBI}$} & $11(20 \%)$ & $11(100 \%)$ & $1(33 \%)$ & $248(8 \%)$ & $266(100 \%)$ & $88(49 \%)$ \\
\hline \multicolumn{2}{|l|}{ ESE and CBI } & $4(7 \%)$ & $5(45 \%)$ & $1(33 \%)$ & $20(1 \%)$ & $16(100 \%)$ & $2(1 \%)$ \\
\hline
\end{tabular}

* In the case of iris melanoma, only the largest basal diameter was mentioned.

AJCC, American Joint Committee on Cancer, $8^{\text {th }}$ edition; CBI, ciliary body involvement; ESE, extrascleral extension. 
3541 (98.1\%; 95\% CI 97.6 to 98.5) patients had no evidence of metastasis (stage I-III disease, group N).

\section{Primary tumour location}

In group $\mathrm{M}, 55(80 \%)$ primary tumours originated in the choroid, $11(16 \%)$ arose in the ciliary body and $3(4 \%)$ were iris melanomas. The corresponding numbers for group N were 3097 (87\%), 266 (8\%) and 178 (5\%), respectively.

Group $\mathrm{M}$ analysis for intraocular tumour location revealed that ciliary body tumour origin was a significant risk factor for metastasis at initial presentation (OR 2.34, 95\% CI 1.21 to $4.50 ; p=0.011)$. Likewise, choroidal tumours with ciliary body involvement were at an equally high risk of synchronous metastasis (OR 2.87, 95\% CI 1.46 to 5.63; $\mathrm{p}=0.02$ ).

\section{Eighth edition AJCC staging - T category}

In group $\mathbf{M}$, choroidal melanomas were classified as 5 (9\%) T1, 18 (33\%) T2, 16 (29\%) T3 and 16 (29\%) T4. For ciliary body melanoma, the corresponding values were 1 (9\%), 2 (18\%), 7 $(64 \%)$ and 1 (9\%). For iris melanomas, which were classified separately, $2(67 \%)$ were T1 and $1(33 \%)$ was T4 (tables 1 and $2)$. Overall, the percentage of patients with stage IV disease increased by $\mathrm{T}$-category from $0.7 \% \mathrm{~T} 1,1.5 \% \mathrm{~T} 2,2.6 \% \mathrm{~T} 3$ and $7.9 \%$ in $\mathrm{T} 4$

A bivariate logistic regression was performed to ascertain the effects of AJCC T-category and subcategory on the likelihood that patients with uveal melanoma have synchronous metastasis (table 3). The logistic regression model was statistically significant, $\chi 2(7)=51.59, \mathrm{p}<0.001$. The model explained $8.2 \%$ (Nagelkerke $R 2$ ) of the variance in synchronous metastasis and correctly classified $98.1 \%$ of cases. Here, we see that risk for metastases at diagnosis, even when controlling for intraocular and extraocular invasion, increases logically with increasing T1T4 (1.0-2.3-3.5-7.6) and the OR of course is somewhat eroded because 'a-e' takes away part of it. The significances, however, are essentially unaltered compared with univariable. For a-d, the logical increase also is maintained (OR 1.00-1.3-3.4-7.2) though ' $\mathrm{e}$ ' than can be a tumour of any $\mathrm{T}$ if extraocular extension is $>5 \mathrm{~mm}$ does not follow the rule. The significance of ' $b$ ' is much eroded, indicating that in the absence of extraocular extension, ciliary body involvement is not contributing much to the added risk given $\mathrm{T}$ size (table 3 ).

On further dividing the group $M$ for eighth edition AJCC T-subcategories table $2, n=69$ shows that there were $6 \%$ of T1a with no ciliary body involvement or extrascleral extension. A majority of $63 \%$ tumours had no ciliary body involvement or extrascleral extension in group $\mathrm{M}$.

\section{Choroidal melanoma}

The median thickness and largest basal diameter of choroidal melanomas in group $\mathrm{M}$ (table $1 ; \mathrm{n}=55$ ) were $7.7 \mathrm{~mm}$ (range 2.0-24.5) and $15.0 \mathrm{~mm}$ (range 2.9-25.0), respectively. The corresponding numbers for group $\mathrm{N}$ were $5.0 \mathrm{~mm}$ (range 2.0-23.0) and $12.0 \mathrm{~mm}$ (range $2.0-30.0$ ), respectively (table $1 ; \mathrm{n}=3097$ ). Both tumour thickness and largest basal diameter were significantly associated with risk of metastasis at presentation (OR

Table 2 Stage IV uveal melanoma at initial presentation (group M)

\begin{tabular}{|c|c|c|c|c|c|c|}
\hline AJCC tumour category & & & Choroidal $n=55$ & Ciliary body $n=11$ & Iris $n=3$ & Total $\mathrm{n}=69$ \\
\hline \multirow[t]{17}{*}{ T-category } & T1a & No CBI/ESE & $4(7 \%)$ & $0(0 \%)$ & $0(0 \%)$ & $4(6 \%)$ \\
\hline & $\mathrm{T} 1 \mathrm{~b}$ & CBI only & $0(0 \%)$ & $1(9 \%)$ & $2(67 \%)$ & $3(4 \%)$ \\
\hline & T1c & ESE only $(\leq 5 \mathrm{~mm})$ & $1(2 \%)$ & $0(0 \%)$ & $0(0 \%)$ & $1(1 \%)$ \\
\hline & T1d & $\begin{array}{l}\text { Both CBI and ESE } \\
(\leq 5 \mathrm{~mm})\end{array}$ & $0(0 \%)$ & $0(0 \%)$ & $0(0 \%)$ & $0(0 \%)$ \\
\hline & $\mathrm{T} 2 \mathrm{a}$ & No CBI/ESE & $17(31 \%)$ & $0(0 \%)$ & $0(0 \%)$ & $17(26 \%)$ \\
\hline & $\mathrm{T} 2 \mathrm{~b}$ & CBI only & $0(0 \%)$ & $2(18 \%)$ & $0(0 \%)$ & $2(3 \%)$ \\
\hline & $\mathrm{T} 2 \mathrm{c}$ & ESE only ( $\leq 5 \mathrm{~mm})$ & $1(2 \%)$ & $0(0 \%)$ & $0(0 \%)$ & $1(1 \%)$ \\
\hline & $\mathrm{T} 2 \mathrm{~d}$ & $\begin{array}{l}\text { Both CBI and ESE } \\
(\leq 5 \mathrm{~mm})\end{array}$ & $0(0 \%)$ & $0(0 \%)$ & $0(0 \%)$ & $0(0 \%)$ \\
\hline & T3a & No CBI/ESE & $13(27 \%)$ & $0(0 \%)$ & $0(0 \%)$ & $13(19 \%)$ \\
\hline & $\mathrm{T} 3 \mathrm{~b}$ & CBI only & $2(4 \%)$ & $3(27 \%)$ & $0(0 \%)$ & $5(7 \%)$ \\
\hline & $\mathrm{T} 3 \mathrm{c}$ & ESE only $(\leq 5 \mathrm{~mm})$ & $0(0 \%)$ & $0(0 \%)$ & $0(0 \%)$ & $0(0 \%)$ \\
\hline & T3d & $\begin{array}{l}\text { Both CBI and ESE } \\
(\leq 5 \mathrm{~mm})\end{array}$ & $1(2 \%)$ & $4(36 \%)$ & $0(0 \%)$ & $5(7 \%)$ \\
\hline & T4a & No CBI/ESE & $8(14 \%)$ & $0(0 \%)$ & $1(33 \%)$ & $9(13 \%)$ \\
\hline & $\mathrm{T} 4 \mathrm{~b}$ & $\mathrm{CBI}$ only & $5(9 \%)$ & $0(0 \%)$ & $0(0 \%)$ & $5(7 \%)$ \\
\hline & $\mathrm{T} 4 \mathrm{c}$ & ESE only $(\leq 5 \mathrm{~mm})$ & $0(0 \%)$ & $0(0 \%)$ & $0(0 \%)$ & $0(0 \%)$ \\
\hline & $\mathrm{T} 4 \mathrm{~d}$ & $\begin{array}{l}\text { Both CBI and ESE } \\
(\leq 5 \mathrm{~mm})\end{array}$ & $2(4 \%)$ & $0(0 \%)$ & $0(0 \%)$ & $2(3 \%)$ \\
\hline & T4e & $\operatorname{ESE}(>5 \mathrm{~mm})$ & $1(2 \%)$ & $1(9 \%)$ & $0(0 \%)$ & $2(3 \%)$ \\
\hline \multirow[t]{8}{*}{ Metastasis sites } & \multicolumn{2}{|c|}{ Regional lymph nodes (N1a) } & $5(9 \%)$ & $4(36 \%)$ & $0(0 \%)$ & $9(13 \%)$ \\
\hline & \multicolumn{2}{|c|}{ Liver } & $38(69 \%)$ & $9(82 \%)$ & $3(100 \%)$ & $50(72 \%)$ \\
\hline & \multicolumn{2}{|c|}{ Lung } & $3(5 \%)$ & $0(0 \%)$ & $0(0 \%)$ & $3(4 \%)$ \\
\hline & \multicolumn{2}{|c|}{ Bone } & $0(0 \%)$ & $0(0 \%)$ & $0(0 \%)$ & $0(0 \%)$ \\
\hline & \multicolumn{2}{|c|}{ Brain } & $0(0 \%)$ & $0(0 \%)$ & $0(0 \%)$ & $(0 \%)$ \\
\hline & \multicolumn{2}{|c|}{ Subcutaneous tissue } & $0(0 \%)$ & $0(0 \%)$ & $0(0 \%)$ & $0(0 \%)$ \\
\hline & \multicolumn{2}{|c|}{ Other sites } & $0(0 \%)$ & $0(0 \%)$ & $0(0 \%)$ & $0(0 \%)$ \\
\hline & \multicolumn{2}{|c|}{ Multiple sites } & $14(26 \%)$ & $2(18 \%)$ & $0(0 \%)$ & $16(24 \%)$ \\
\hline
\end{tabular}

AJCC, American Joint Committee on Cancer, $8^{\text {th }}$ edition; CBI, ciliary body involvement; ESE, extrascleral extension. 


\begin{tabular}{|c|c|c|c|c|c|}
\hline Logistic regression & Variable & & B (SE) & $P$ value & OR $(95 \% \mathrm{Cl})$ \\
\hline \multirow[t]{6}{*}{ Univariate } & AJCC T-category & $\mathrm{T} 1$ & & & 1.0 \\
\hline & & T3 & $1.279(0.413)$ & 0.002 & 3.6 (1.6 to 8.07$)$ \\
\hline & & T4 & $2.410(0.431)$ & $<0.001$ & 11.1 (4.78 to 25.91 ) \\
\hline & AJCC T-subcategory & a & & & 1.0 \\
\hline & & $d$ & $2.621(0.443)$ & $<0.001$ & 13.8 (5.77 to 32.73 ) \\
\hline & & e & $2.409(0.779)$ & 0.002 & 11.1 (2.42 to 51.23$)$ \\
\hline \multirow[t]{6}{*}{ Bivariate } & AJCC T-category & $\mathrm{T} 1$ & & & 1.0 \\
\hline & & $\mathrm{T} 2$ & $0.818(0.423)$ & 0.053 & 2.3 (0.99 to 5.19) \\
\hline & & $\mathrm{T} 3$ & $1.252(0.418)$ & 0.003 & 3.5 (1.54 to 7.93$)$ \\
\hline & & c & $1.232(0.764)$ & 0.107 & 3.4 (0.77 to 15.32$)$ \\
\hline & & $d$ & $1.967(0.481)$ & $<0.001$ & 7.2 (2.78 to 18.36$)$ \\
\hline & & $\mathrm{e}$ & $1.240(0.829)$ & 0.135 & 3.5 (0.68 to 17.54$)$ \\
\hline
\end{tabular}

AJCC, American Joint Committee on Cancer, $8^{\text {th }}$ edition.

$1.21,95 \%$ CI 1.14 to $1.29, \mathrm{p}<0.001$ and OR $1.15,95 \%$ CI 1.08 to $1.22, \mathrm{p}<0.001$, respectively, for each $1 \mathrm{~mm}$ increase).

In group M, 6 (11\%) tumours presented with extrascleral extension (mean diameter of $4.8 \mathrm{~mm}$ (SD 3.1; median 3.5; range $3.0-11.0)), 11(20 \%)$ had ciliary body involvement and $4(7 \%)$ presented with both (table 1). In group N, 48 (2\%) tumours presented with extrascleral extension (mean diameter of $3.7 \mathrm{~mm}$ (SD 4.5; median 2.2; range 0.5-27.0)), 248 (8\%) had ciliary body involvement and $20(1 \%)$ had both (table 1). All three characteristics predicted metastasis at initial presentation (OR $7.78,95 \%$ CI 3.18 to $19.02, \mathrm{p}<0.001$; OR $2.87,95 \%$ CI 1.46 to $5.63, \mathrm{p}=0.02$ and OR $12.07,95 \%$ CI 3.98 to $36.56, \mathrm{p}<0.001$, respectively).

\section{Ciliary body melanoma}

Ciliary body melanomas in group $M(n=11)$ had a median tumour thickness and largest basal diameter of $11.0 \mathrm{~mm}$ (range 2.7-14.7) and 9.1 mm (range 6.0-13.8), respectively. In comparison, group $\mathrm{N}(\mathrm{n}=266)$ median tumour thickness and largest basal dimensions were $5.6 \mathrm{~mm}$ (range $2.0-16.0$ ) and $11.0 \mathrm{~mm}$ (range 2.0-14.0), respectively (table 1). In this comparison, tumour thickness was significantly associated with risk of metastasis at presentation (OR 1.37, 95\% CI 1.14 to $1.64, \mathrm{p}=0.001$, for each $1 \mathrm{~mm}$ increase) unlike largest basal diameter $(\mathrm{p}=0.78)$.

In group M 5 (45\%) patients presented with extrascleral extensions with a mean diameter of $4.9 \mathrm{~mm}$ (SD 2.0; median 5.0; range 3.0-8.0) as compared with $16(6 \%)$ patients in group $\mathrm{N}$ who had extrascleral extensions with a mean diameter of $6.2 \mathrm{~mm}$ (SD 11.8; median 3.4; range 1.0-50.0) (table 1). Therefore, the presence of extrascleral extension was a predictor of metastasis at initial presentation (OR 13.02, 95\% CI 3.58 to 47.30, $\mathrm{p}=0.001)$.

\section{Iris melanoma}

In group $\mathrm{M}$, the three iris melanomas were 5, 6.8 and $9 \mathrm{~mm}$ in diameter. These measurements were compared with median $3.0 \mathrm{~mm}$ (range $0.5-19.0)$ from group $\mathrm{N}(\mathrm{n}=178$; table 1$)$. In group $\mathrm{M}$, there was 1 patient who presented with both extrascleral extension and ciliary body involvement as compared with 88 (49\%) patients who had ciliary body involvement and 2 patients who presented with both extrascleral extension and ciliary body involvement in group $\mathrm{N}$ (table 1 ). In group $\mathrm{M}$, the number of patients with iris melanoma metastases was small, thus risk-based statistical analysis was not possible.

\section{RLN-N category}

The eighth edition AJCC defined N category for RLN metastasis (N1) primarily exists in cases of uveal melanoma with extrascleral extension. As described in the eighth edition AJCC Uveal Melanoma Chapter, anterior extrascleral extension is thought to invade conjunctival lymphatics to reach regional (preauricular and cervical) lymph nodes (N1a). ${ }^{1}$ In contrast, tumour deposits in the orbit (associated with extrascleral extension) were considered to be a rare cause of regional nodal spread (N1b). ${ }^{1}$ In group M, $9(13 \%)$ patients were staged to N1a (table 2). All had either a ciliary body or a choroidal melanoma (table 2). Of these, 2 (3\%) had metastases to preauricular RLN, $3(4 \%)$ to cervical RLN, $3(4 \%)$ had both preauricular and submandibular RLN metastases and the metastases in one patient involved all regional RLN locations. Of the nine patients with RLN metastases (N1a), six $(67 \%)$ were reported to have extrascleral extension.

\section{Systemic metastases-M category}

Distant metastasis (M1) is graded in the TNM system by the size of the largest diameter of the largest metastasis: $\leq 3.0 \mathrm{~cm}$ (M1a), $3.1-8.0 \mathrm{~cm}$ (M1b) and $\geq 8.1 \mathrm{~cm}$ (M1c). ${ }^{1}$ This diameter of the largest metastasis was recorded for $40(59 \%)$ patients in group M. Of these, 14 (35\%) were M1a, 25 (63\%) were M1b and $1(2 \%)$ was M1c. The mean largest diameter was $4.3 \mathrm{~cm}$ (SD 3.2; median 4.0; range 1.0-22.0).

Regarding the sites of systemic metastases, hepatic metastases were noted in 63 (91\%) patients. Of these, metastases noted as liver-alone were noted in 46 (67\%; tables 2 and 4). Of the 69 patients, extrahepatic organs included: 11 (16\%) to lung, $6(9 \%)$ bone, 4 (6\%) brain, 3 (4\%) subcutaneous, 2 (3\%) visceral lymph nodal metastases and 1 splenic metastasis. Overall, multiple sites of metastasis were found in $16(24 \%)$ of patients (table 2). Of those 6 (9\%) patients who presented with extrahepatic 
Table 4 Hepatic metastases based on staging method and AJCC T-category

\begin{tabular}{|c|c|c|c|c|}
\hline \multirow[b]{2}{*}{ T-category } & \multicolumn{2}{|c|}{ Hepatic metastases only } & \multicolumn{2}{|c|}{ Hepatic metastases and involvement of other sites } \\
\hline & $\begin{array}{l}\text { Not staged by PET/CT } \\
\mathrm{N}=23\end{array}$ & $\begin{array}{l}\text { Staged by PET/CT } \\
\mathrm{N}=23\end{array}$ & $\begin{array}{l}\text { Not staged by PET/CT } \\
\mathrm{N}=7\end{array}$ & $\begin{array}{l}\text { Staged by PET/CT } \\
\mathrm{N}=10\end{array}$ \\
\hline $\mathrm{T} 1$ & $3(12 \%)$ & $4(17 \%)$ & $0(0 \%)$ & $0(0 \%)$ \\
\hline $\mathrm{T} 2$ & $5(22 \%)$ & $4(17 \%)$ & $6(86 \%)$ & $3(30 \%)$ \\
\hline T3 & $5(22 \%)$ & $10(44 \%)$ & $1(14 \%)$ & $5(50 \%)$ \\
\hline T4 & $10(44 \%)$ & $5(22 \%)$ & $0(0 \%)$ & $2(20 \%)$ \\
\hline
\end{tabular}

.AJCC, American Joint Committee on Cancer, 8th edition; PET, positron emission tomography; PET/CT, combination PET with synchronous CT analysis.

dissemination, 3 (4.5\%) had multiorgan involvement and 3 (4.5\%) had lung metastasis.

\section{Radiographic imaging}

PET/CT scan was performed for 340 (9\%) of the 3610 patients, including 37 (54\%) in group M (table 4) and 303 (9\%) in group $\mathrm{N}$. In group $\mathrm{M}$, out of 16 patients with metastases in multiple sites, $8(50 \%)$ were diagnosed by PET/CT scan whereas $8(50 \%)$ were diagnosed by other staging methods at initial presentation. In addition PET/CT also helped in identifying of 5 (56\%) RLN. Metastases in multiple sites and RLN were identified by PET/ CT more often than without $(\mathrm{p}<0.001)$. This finding suggests underdiagnosis of multiorgan metastasis when using regional organ-specific staging methods.

\section{Survival after diagnosis}

Median follow-up from initial presentation to last visit of group $\mathrm{M}$ was 10.0 months (mean 18.2; SD 19.5; range 1.0-85.0). The corresponding numbers for group $\mathrm{N}$ were 38.6 months (mean 47.2; SD 34.9; range 0.9-212.0). The survival time was calculated for $53(77 \%)$ patients in group M. For the rest, survival time was not considered as it exceeded the date of closure of the registry. Group $\mathrm{M}$ had a median survival of 12.0 months (mean 20.0; SD 21.3; range 2.0-91.0).

\section{DISCUSSION}

This study uniquely describes the clinical features of stage IV patients identified with metastatic uveal melanoma at the time of initial presentation. These cases were designated patients with stage IV uveal melanoma by the eighth edition AJCC staging system $^{1}$ and derived from the AJCC-OOTF international, multicentre, internet-based registry which collected 3866 cases. From that series we analysed a subgroup of 69 stage IV patients for statistically significant differences. Predictive factors for metastasis at initial presentation included: site of origin, tumour thickness, largest basal diameter, extrascleral extension, ciliary body involvement and eighth edition AJCC-TNM category. These characteristics differed in patients with and without synchronous metastases at presentation. Furthermore, we found that wholebody radiographic imaging was more likely to reveal extrahepatic and multiorgan sites of metastasis.

As early as 1979 , Zimmerman and McLean ${ }^{35}$ published a case series of 29 patients of uveal melanoma with metastasis describing their presenting history and symptoms. Our study is unique as it describes the ocular and systemic, eighth edition AJCC staging of patients with presenting with both uveal melanoma and metastasis.

\section{Sites of tumour origin}

The intraocular location of a uveal melanoma has been shown to influence metastatic risk. Ciliary body location has been associated with a higher mortality rate. ${ }^{15} 193236$ We also found that ciliary body origin was associated with metastases at initial presentation. Ciliary body and choroidal location with extrascleral extension were associated with RLN metastases in nine patients.

\section{Tumour size}

Tumour thickness was a significant predictor for stage IV disease at the time of presentation for both choroidal and ciliary body melanomas. However, largest basal diameter was only statistically significant for choroidal melanomas. Lack of an association for ciliary body melanomas possibly was related to the small number of tumours in that location and difficulties related to their measurement. Overall, our findings were consistent with prior studies, suggesting patients with a higher T-category tumour should be more closely monitored for metastatic disease. ${ }^{1-3} 5153437$ Novel finding of this study was that there were $6 \%$ of the uveal melanoma with metastasis at initial presentation which belong to subcategory T1a. This emphasises the importance of periodic surveillance even for small tumours perhaps (ie, eighth edition AJCC cT1).

\section{Extrascleral extension and ciliary body involvement}

For choroidal and ciliary body melanoma, presence of extrascleral extension was associated with a significantly higher frequency for synchronous metastasis. However, ciliary body involvement was also associated with synchronous metastases in choroidal melanoma. These findings are consistent with prior studies relating to metastases developing on follow-up. 1213173137 It is reasonable to conclude that the presence of ciliary body involvement, extrascleral extension or both on the first visit should raise suspicion for synchronous metastatic melanoma.

\section{$\mathrm{N}$ and $\mathrm{M}$ categories}

It can be inferred from table $5^{517203839}$ that uveal melanoma metastasises to multiple sites, with the liver being the most frequent. However, the liver is both the most commonly investigated organ and thus selected to be the most common initially reported sites of metastasis. In comparison to other research, our group M study was unique in that whole-body PET/CT imaging was compared for initial staging. In our study, whole-body initial staging enabled early detection of multiple organ metastasis in 50\% of 16 stage IV patients in group M. Table 5 shows that uveal melanoma can metastasise to extrahepatic sites and in some cases may involve multiple sites. For example, Kath et al detected multiple site metastasis on long-term follow-up in 54\% of patients. ${ }^{38}$ Failure to detect extrahepatic or multiorgan metastasis can affects treatment decisions and thus patient survival duration. ${ }^{831}$

\section{Survival time}

The relatively short 12 months median survival time for group $\mathrm{M}$ could be related to relatively high T-categories, one can find 
Table 5 Comparison of metastatic sites of uveal melanoma among various studies

\begin{tabular}{|c|c|c|c|c|c|c|c|}
\hline Study & Rajpal $^{20}$ & $\mathrm{COMS}^{5}$ & Kath $^{38}$ & Rietschel $^{17}$ & Jochems $^{39}$ & Mean & Our study \\
\hline Metastasis & $F / U$ & F/U & F/U & F/U & $\mathrm{F} / \mathrm{U}$ & $\mathrm{F} / \mathrm{U}$ & Presentation \\
\hline Sample size & 35 & 739 & 24 & 119 & 175 & 218.4 & 69 \\
\hline Liver & $71.4 \%$ & $89.0 \%$ & $87.0 \%$ & $60.5 \%$ & $88.0 \%$ & $79.2 \%$ & $91.3 \%$ \\
\hline Lungs & $40.0 \%$ & $29.0 \%$ & $46.0 \%$ & $24.4 \%$ & $25.1 \%$ & $32.9 \%$ & $15.9 \%$ \\
\hline Lymph nodes & $14.3 \%$ & $11.0 \%$ & $4.2 \%$ & $1.7 \%$ & $16.0 \%$ & $9.4 \%$ & $13.0 \%$ \\
\hline Bones & $17.1 \%$ & $17.0 \%$ & $29.0 \%$ & $8.4 \%$ & $15.4 \%$ & $17.4 \%$ & $8.7 \%$ \\
\hline Brain & $5.7 \%$ & $6.1 \%$ & $8.0 \%$ & $4.2 \%$ & $1.7 \%$ & $5.1 \%$ & $5.8 \%$ \\
\hline Subcutaneous tissue & $34.3 \%$ & $12.0 \%$ & $17.0 \%$ & $10.9 \%$ & $10.3 \%$ & $16.9 \%$ & $4.3 \%$ \\
\hline Others & $34.3 \%$ & $11.0 \%$ & $37.5 \%$ & N/A & $23.4 \%$ & $26.6 \%$ & $4.2 \%$ \\
\hline Multiple sites & $\mathrm{N} / \mathrm{A}$ & $43.0 \%$ & $54.2 \%$ & $10.9 \%$ & $5.7 \%$ & $28.4 \%$ & $23.2 \%$ \\
\hline Tests & $N / A$ & $\begin{array}{l}\text { LFTs, CXR and } \\
\text { autopsy studies }\end{array}$ & $\begin{array}{l}\text { LFTs, CXR, } \\
\text { abdominal USG, } \\
\text { CT, MRI and } \\
\text { autopsy studies }\end{array}$ & $\begin{array}{l}\text { Radiographic } \\
\text { imaging, blood test }\end{array}$ & $\begin{array}{l}\text { Lactose dehydrogenase enzyme } \\
\text { (LDH), Radiographic imaging }\end{array}$ & N/A & $\begin{array}{l}\text { Abdominal } \\
\text { USG, CT, MRI, } \\
\text { and whole- } \\
\text { body- PET or } \\
\text { PET/CT }\end{array}$ \\
\hline $\begin{array}{l}\text { Median survival time in months } \\
\text { (time of metastasis to death) }\end{array}$ & $2.2^{*}$ & $<6$ & 13.2 & 12.5 & One-year survival- $47.8 \%$ & $-\dagger$ & 12 \\
\hline
\end{tabular}

*For Rajpal ${ }^{20}$ median survival time of liver metastasis was mentioned as there was no mention of cumulative survival time and hepatic metastasis was most common. tMean was not calculated for median survival time.

CXR, chest X-ray; F/U, at follow-up; LFTS, liver function tests; PET, positron emission tomography; PET/CT, combination PET and CT analysis; USG, ultrasonography.

similar survival times in other studies. ${ }^{6}{ }^{19-27}$ Clearly, group M patients had demonstrable late stage, multiorgan disease associated with impending death. Therefore, their relatively short survival was likely related to 'late-stage selection bias'.

\section{Surveillance}

Table 5 emphasises the importance of surveilling the whole body for metastasis. Although hepatic metastases can be discovered in up to $90 \%$ of cases with hepatic USG or contrast enhanced abdominal CT or MRI, the challenge lies in detecting extrahepatic spread. ${ }^{9}$ In an effort to screen the whole body, Freton et al studied initial staging of uveal melanoma in 333 consecutive patients with PET/CT. He found that whole-body imaging improved not only detection of extrahepatic metastases but also revealed that $3.3 \%$ of patients had additional non-ocular primary cancers. ${ }^{8}$ The complex of concerns regarding the use of each diagnostic method is beyond the scope of this study but has been related to dependence on skilled technicians (USG), radiation dose (PET/CT >CT), side effects of contrast agents (MRI>CT) and relative cost. ${ }^{3894041}$

Various studies have compared different modalities of imaging for detection of metastasis from tumours in other sites (eg, solitary pulmonary nodule and cervical carcinoma). Yi et al reported $\mathrm{PET} / \mathrm{CT}$ is more accurate and sensitive in identifying malignant solitary pulmonary nodules. In contrast, the sensitivity, specificity and accuracy for a malignant solitary pulmonary nodule on high-resolution CT scan were $81 \%, 93 \%$ and $85 \%$, respectively, whereas those on integrated PET/CT were 96\%, 88\% and 93\%, respectively. ${ }^{40}$ Similarly, Liu et al performed a meta-analysis on 67 studies on cervical carcinoma, concluded that PET/CT has the highest specificity to identify lymph nodes among non-invasive imaging modalities. ${ }^{41}$ In our study, PET/CT was significantly more likely to reveal multiorgan metastasis.

\section{CONCLUSION}

We describe patients who initially presented with stage IV uveal melanoma. They were more likely to have tumours with ciliary body origin or involvement, larger tumour thicknesses, greater basal diameters and extrascleral extension. These factors were reflected by their higher eighth edition AJCC TNM categories. $^{8}$ We found that stage IV patients were more likely to have multiorgan disease, most often detected by whole-body PET/CT imaging. However, even T1 uveal melanomas may present with synchronous metastasis. Therefore, this study supports initial whole-body staging of all patients with uveal melanoma.

\section{Author affiliations}

'Department of Ocular Tumor, Orbital Disease, Ophthalmic Radiation Therapy, New York Eye Cancer Center, New York, New York, USA

${ }^{2}$ Ocular Oncology Service, Helsinki University Central Hospital, Helsinki, Finland

${ }^{3}$ Department of Ocular Oncology, Princess Margaret Hospital Cancer Centre, Toronto, Ontario, Canada

${ }^{4}$ Departments of Molecular Medical Genetics, Medical Biophysics, and

Ophthalmology, Princess Margaret Hospital Cancer Centre, Toronto, Ontario, Canada ${ }^{5}$ Department of Ophthalmic Oncology and Radiology, Moscow Helmholtz Research

Institute of Eye Diseases, Moskva, Russian Federation

${ }^{6}$ Department of Ophthalmic Pathology and Oncology, Saint Eriks Eye Hospital, Stockholm, Sweden

${ }^{7}$ The Ophthalmic Oncology Service, Hamilton Eye Institute, The University of Tennessee Health Science Center, Memphis, Tennessee, USA

${ }^{8}$ Ocular Oncology Service, Bellvitge University Hospital, L'Hospitalet de Llobregat, Barcelona, Spain

${ }^{9}$ Department of Ophthalmic Oncology, Hospital General de Agudos Carlos G Durand, Buenos Aires, Argentina

${ }^{10}$ Department of Ophthalmology, Leiden University Medical Center, Leiden, The Netherlands

${ }^{11}$ Department of Ophthalmic Oncology, Cleveland Clinic Foundation, Cleveland, Ohio, USA

${ }^{12}$ Department of Ophthalmic Oncology, National Cancer Center Hospital, Tokyo, Japan

\section{Twitter Paul T Finger @\#paulfingermd}

Collaborators Paul T. Finger, MD (Chair) New York Eye Cancer Center, New York); Sarah E. Coupland, MBBS, PhD, FRCPath (Vice Chair) (Royal Liverpool University Hospital, Liverpool, United Kingdom); Daniel M. Albert, MD, MS (Oregon Health and Sciences University, Portland); Anush G. Amiryan, MD, and Svetlana Saakyan, MD (Moscow Helmholtz Research Institute of Eye Disease, Moscow, Russian Federation); Claudia Auw-Hädrich, MD (University of Freiburg, Freiburg, Germany); Diane Baker, CTR (American Joint Committee on Cancer, Chicago, Illinois); Raymond Barnhill, MD, MSc (UCLA Medical Center, Los Angeles); José M. Caminal, MD, PhD (Bellvitge University Hospital - University of Barcelona, L'Hospitalet de Llobregat, Barcelona, Spain); William L. Caroll, MD (New York University Cancer Institute - New York University Langone Medical, New York); Nathalie Cassoux, MD, PhD, Laurence G. Desjardins, MD, François Doz, MD, MSc, and Gaelle Pierron, PhD (Institut Curie, 
Paris, France); Jaume Catalá-Mora, MD (Bellvitge University Hospital - University of Barcelona, L'Hospitalet de Llobregat, Barcelona, Spain); Guillermo Chantada, MD (Hospital JP Garrahan, Buenos Aires, Argentina); Patricia Chévez-Barrios, MD (Houston Methodist Hospital, Houston, Texas); R. Max Conway, MD, PhD (Save Sight Institute, Sydney, Australia); Bertil E. Damato, MD, PhD (University of California, San Francisco, San Francisco); Hakan Demirci, MD (Kellogg Eye Center, Ann Arbor, Michigan); Jonathan J. Dutton, MD, PhD (University of North Carolina, Chapel Hill); Bita Esmaeli, MD, Victor G. Prieto, MD, PhD, and Michelle Williams, MD (University of Texas MD Anderson Cancer Center, Houston); Brenda L. Gallie, MD (Princess Margaret Cancer Centre, Toronto, Ontario, Canada); Gerardo F. Graue, MD (Instituto de Oftalmología Fundación Conde de Valenciana, Mexico City, Mexico); Hans E. Grossniklaus, MD (Emory Eye Center, Atlanta, Georgia); Steffen Heegaard, MD, PhD (University of Copenhagen, Glostrup Hospital, Copenhagen, Denmark); Leonard M. Holbach, MD (University Erlangen, Nürnberg, Germany); Santosh G. Honavar, MD (Centre For Sight Super-Specialty Eye Hospital, Hyderabad, India); Martine J. Jager, MD, PhD (Leiden University Medical Center, Leiden, the Netherlands); Tero Kivelä, MD, FEBO, and Emma Kujala, MD (Helsinki University Central Hospital, Helsinki, Finland); Livia Lumbroso-Le Rouic, MD (Institute Claudius Regaud Medical Center, Toulouse, France); Ashwin C. Mallipatna, MBBS, MS, DNB (Princess Margaret Cancer Centre, Toronto, Canada); Giulio M. Modorati, MD (San Raffaele Hospital, Milan, Italy); Francis L. Munier, MD (Jules-Gonin Eye Hospital, Lausanne, Switzerland); Timothy G. Murray, MD, MBA (Murray Ocular Oncology and Retina, Coral Gables, Florida); Anna C. Pavlick, MD (New York University Cancer Center, New York); Jacob Pe'er, MD (Hebrew University, Hadassah Ein Karem Hospital, Jerusalem, Israel); David E. Pelayes, MD (Hospital General de Agudos Carlos G Durand, Buenos Aires University, Buenos Aires, Argentina); Manuel Rodrigues, MD (Medical Oncology Departement, INSERM U830 laboratory, Paris); Wolfgang A.G. Sauerwein, MD, PhD (University Hospital Essen, Essen, Germany); Ekaterina Semenova, MD (The New York Eye Cancer Center, New York); Stefan Seregard, MD (Saint Eriks Eye Hospital, Stockholm, Sweden); Carol Shields, MD (Wills Eye Institute, Philadelphia, Pennsylvania); E. Rand Simpson, MD, FRCS(C) (Princess Margaret Cancer Centre, Toronto, Ontario, Canada); Arun D. Singh, MD (Cleveland Clinic Foundation, Cleveland Clinic, Cleveland, Ohio); Shigenobu Suzuki, MD, PhD (National Cancer Center Hospital, Tokyo, Japan); Mary Kay Washington, MD, PhD (Vanderbilt University Medical Center, Nashville, Tennessee); Valerie A. White, MD, MHSc, FRCPC (Vancouver Coastal Health Research Institute, Vancouver, British Columbia, Canada); Mathew W. Wilson, MD (University of Tennessee Health Science Center, Memphis); Christian W. Wittekind, MD (Institut fur Pathologie der Universität, Leipzig, Germany); and Vivian Yin, MPH (Memorial Sloan Kettering Cancer Center, New York, New York).

Contributors PT Finger, G Garg and TT Kivela: study conception and design, analysis and interpretation of data, and drafting of manuscript. PTF: study conception and design, acquisition of data, analysis and interpretation of data, drafting of manuscript, and critical revision; Drs. ER Simpson, BL Gallie, S Saakyan, A Amiryan, KJ Chin, JM Caminal, E Semenova, S Seregard, M Fili, M Wilson, JM Caminal, JC Mora, C Gutierrez, DE Pelayes, AM Folgar, MJ Jager, MD, GPM Luyten, AD Singh, S Suzuki; V Valskiy, B Haik: study conception and design and acquisition of data. Yuliya Gavrylyuk, MD, MHA, Princess Margaret Cancer Centre, Toronto, Ontario, Canada, assisted with multicentre institutional review board, ethics committee, privacy and other contractual relationships.

Funding This study was funded by internet technology grants to Princess Margaret Cancer Center's IT program, which has (in turn) participated in the design, construction and maintenance of this uveal melanoma registry. Funders included John and Myrna Daniels Foundation, The Paul T Finger Fund for Ophthalmic Oncology Research and The Eye Cancer Foundation. (http://eyecancercure.com). Dr Garg received an ophthalmic oncology fellowship grant to study with Dr Finger (from The Eye Cancer Foundation). Dr Kivelä reported receiving a governmental grant from the Helsinki University Hospital Research Fund.

\section{Competing interests None declared.}

Patient consent for publication Not required.

Ethics approval Institutional review board and ethics approvals were written and obtained by each participating centre based on and including required elements from the Princess Margaret Comprehensive Cancer Center of Toronto, Ontario, Canada Internet Technology Protocols. These approvals allowed anonymised patient data to be entered, online into the central database. This study adhered to the Declaration of Helsinki and Health Insurance Portability and Accountability Act of 1986.

Provenance and peer review Not commissioned; externally peer reviewed.

Data availability statement Data are available upon reasonable request. All data relevant to the study are included in the article or uploaded as supplementary information. All data relevant to the study are included in the article or uploaded as supplementary information. Data are available upon reasonable request.

Author note All authors participated in critical review of the manuscript prior to publication (except Drs. Vladimir Valskiy and Barrett Haik who are deceased).

Open access This is an open access article distributed in accordance with the Creative Commons Attribution Non Commercial (CC BY-NC 4.0) license, which permits others to distribute, remix, adapt, build upon this work non-commercially, and license their derivative works on different terms, provided the original work is properly cited, appropriate credit is given, any changes made indicated, and the use is non-commercial. See: http://creativecommons.org/licenses/by-nc/4.0/.

\section{ORCID iDs}

Paul T Finger http://orcid.org/0000-0002-8111-3896

Maria Fili http://orcid.org/0000-0003-4398-9755

Arun D Singh http://orcid.org/0000-0001-9411-0320

\section{REFERENCES}

1 Kivelä T, Simpson ER, Grossniklaus HE, et al. Chapter 67: Uveal Melanoma. Ophthalmic Sites: Part XV. In: Amin MB, Edge S, Greene F, et al, eds. Ajcc cancer staging manual. 8th ed. New York, NY: Springer, 2017: 805-18.

2 Finger PT, Pavlick AC. Intraocular melanoma. In: DeVita VT, Lawrence TS, Rosenberg SA, eds. Cancer: principles and practice of oncology. 11th edn. Dordrecht: Wolters Kluwer, 2019: 1899-908.

3 Pavlick AC, Finger PT. Systemic Evaluation and Management of Patients with Metastatic Uveal Melanoma. In: Ryan's Retina. 6th edn. Elsevier, 2018: 2608-12.

4 Diener-West M, Reynolds SM, Agugliaro DJ, et al. Screening for metastasis from choroidal melanoma: the Collaborative ocular melanoma Study Group report 23. J Clin Oncol 2004;22:2438-44.

5 Diener-West M, Reynolds SM, Agugliaro DJ, et al. Development of metastatic disease after enrollment in the COMS trials for treatment of choroidal melanoma: collaborative ocular melanoma Study Group report No. 26. Arch Ophthalmol 2005;123:1639-43.

6 Collaborative Ocular Melanoma Study Group. The COMS randomized trial of iodine 125 brachytherapy for choroidal melanoma: $\mathrm{V}$. Twelve-year mortality rates and prognostic factors: COMS report No. 28. Arch Ophthalmol 2006;124:1684-93.

7 Eskelin S, Pyrhönen S, Summanen $\mathrm{P}$, et al. Screening for metastatic malignant melanoma of the uvea revisited. Cancer 1999;85:1151-9.

8 Freton A, Chin KJ, Raut R, et al. Initial PET/CT staging for choroidal melanoma: AJCC correlation and second nonocular primaries in 333 patients. Eur J Ophthalmol 2012:22:236-43.

9 Rantala ES, Peltola E, Helminen $H$, et al. Hepatic ultrasonography compared with computed tomography and magnetic resonance imaging at diagnosis of metastatic uveal melanoma. Am J Ophthalmol 2020;216:156-64.

10 Avakyan KV, Saakyan SV, Amiryan AG, et al. The role of modern methods in early metastases diagnosis in patients with uveal melanoma. Rejr 2016;6:8-18.

11 Chen L. Ocular lymphatics: state-of-the-art review. Lymphology 2009;42:66-76.

12 Tojo D, Wenig BL, Resnick KI. Incidence of cervical metastasis from uveal melanoma: implications for treatment. Head Neck 1995;17:137-9.

13 Lorigan JG, Wallace S, Mavligit GM. The prevalence and location of metastases from ocular melanoma: imaging study in 110 patients. AJR Am J Roentgenol 1991;157:1279-81.

14 Collaborative Ocular Melanoma Study Group. Assessment of metastatic disease status at death in 435 patients with large choroidal melanoma in the Collaborative ocular melanoma study (COMS): COMS report No. 15. Arch Ophthalmol 2001;119:670-6.

15 AJCC Ophthalmic Oncology Task Force. International validation of the American joint Committee on cancer's 7th edition classification of uveal melanoma. JAMA Ophthalmol 2015;133:376-83.

16 Eskelin S, Pyrhönen S, Hahka-Kemppinen M, et al. A prognostic model and staging for metastatic uveal melanoma. Cancer 2003:97:465-75.

17 Rietschel $\mathrm{P}$, Panageas KS, Hanlon C, et al. Variates of survival in metastatic uveal melanoma. J Clin Oncol 2005;23:8076-80.

18 Cerbone L, Van Ginderdeuren R, Van den Oord J, et al. Clinical presentation, pathological features and natural course of metastatic uveal melanoma, an orphan and commonly fatal disease. Oncology 2014;86:185-9.

19 Damato BE, Heimann $\mathrm{H}$, Kalirai $\mathrm{H}$, et al. Age, survival predictors, and metastatic death in patients with choroidal melanoma: tentative evidence of a therapeutic effect on survival. JAMA Ophthalmol 2014;132:605-13.

20 Rajpal S, Moore R, Karakousis CP. Survival in metastatic ocular melanoma. Cancer 1983;52:334-6.

21 Finger PT, Chin KJ, Duvall G, et al. Palladium-103 ophthalmic plaque radiation therapy for choroidal melanoma: 400 treated patients. Ophthalmology 2009;116:790-6.

22 Kim IK, Lane AM, Gragoudas ES. Survival in patients with presymptomatic diagnosis of metastatic uveal melanoma. Arch Ophthalmol 2010;128:871-5.

23 Khoja L, Atenafu EG, Suciu S, et al. Meta-Analysis in metastatic uveal melanoma to determine progression free and overall survival benchmarks: an international rare cancers initiative (IRCI) ocular melanoma study. Ann Oncol 2019;30:1370-80.

24 Rantala ES, Hernberg M, Kivelä TT. Overall survival after treatment for metastatic uveal melanoma: a systematic review and meta-analysis. Melanoma Res 2019:29:561-8.

25 Lorenzo D, Ochoa M, Piulats JM, et al. Prognostic factors and decision tree for longterm survival in metastatic uveal melanoma. Cancer Res Treat 2018;50:1130-9.

26 Lorenzo D, Piulats JM, Ochoa M, et al. Clinical predictors of survival in metastatic uveal melanoma. Jpn J Ophthalmol 2019;63:197-209. 
27 Cunha Rola A, Taktak A, Eleuteri A, et al. Multicenter external validation of the Liverpool uveal melanoma prognosticator online: an OOG collaborative study. Cancers 2020;12:477.

28 Aoyama T, Mastrangelo MJ, Berd D, et al. Protracted survival after resection of metastatic uveal melanoma. Cancer 2000;89:1561-8.

29 Sato T. Locoregional management of hepatic metastasis from primary uveal melanoma. Semin Oncol 2010;37:127-38.

30 Morkos M, Jain P, Pavlick AC, et al. Ipsilateral metastatic choroidal melanoma responds to systemic immunotherapy. Eur J Ophthalmol 2020;30:NP69-73. doi:10.1177/1120672119839925

31 Kujala E, Mäkitie T, Kivelä T. Very long-term prognosis of patients with malignant uveal melanoma. Invest Ophthalmol Vis Sci 2003;44:4651-9.

32 Kujala E, Damato B, Coupland SE, et al. Staging of ciliary body and choroidal melanomas based on anatomic extent. J Clin Oncol 2013;31:2825-31.

33 Kivelä TT, Piperno-Neumann S, Desjardins L, et al. Validation of a prognostic staging for metastatic uveal melanoma: a collaborative study of the European ophthalmic Oncology Group. Am J Ophthalmol 2016;168:217-26.

34 Shields CL, Furuta M, Thangappan A, et al. Metastasis of uveal melanoma millimeterby-millimeter in 8033 consecutive eyes. Arch Ophthalmol 2009;127:989-98.
35 Zimmerman LE, McLean IW. Metastatic disease from untreated uveal melanomas. Am J Ophthalmol 1979;88:524-34.

36 Kaliki S, Shields CL, Shields JA. Uveal melanoma: estimating prognosis. Indian J Ophthalmol 2015;63:93-102.

37 Shields CL, Kaliki S, Furuta M, et al. American joint Committee on cancer classification of posterior uveal melanoma (tumor size category) predicts prognosis in 7731 patients. Ophthalmology 2013;120:2066-71.

38 Kath R, Hayungs J, Bornfeld N, et al. Prognosis and treatment of disseminated uveal melanoma. Cancer 1993;72:2219-23.

39 Jochems A, van der Kooij MK, Fiocco M, et al. Metastatic uveal melanoma: treatment strategies and Survival-Results from the Dutch melanoma treatment registry. Cancers 2019;11:1007. doi:10.3390/cancers11071007

40 Yi CA, Lee KS, Kim B-T, et al. Tissue characterization of solitary pulmonary nodule: comparative study between helical dynamic CT and integrated PET/CT. J Nucl Med 2006;47:443-50.

41 Liu B, Gao S, Li S. A comprehensive comparison of CT, MRI, positron emission tomography or positron emission Tomography/CT, and diffusion weighted ImagingMRI for detecting the lymph nodes metastases in patients with cervical cancer: a meta-analysis based on 67 studies. Gynecol Obstet Invest 2017;82:209-22. 